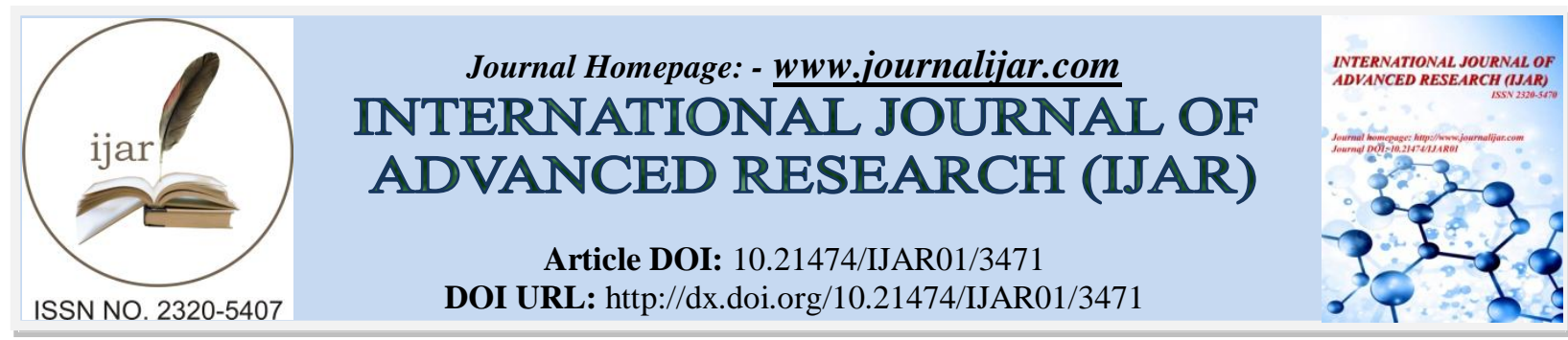

RESEARCH ARTICLE

\title{
MANAGEMENT OF MYOFASCIAL PAIN DYSFUNCTION SYNDROME BY USING DIFFERENT CONCEPT OF OCCLUSION: A SYSTEMATIC REVIEW.
}

\author{
Mona Samir*,1, Mohamed El-Zawahry ${ }^{2}$ and Ahmed Fayad ${ }^{3}$. \\ 1. Msc, Assistant Lecturer, Department Removable, Prosthodontics National Research Centre. \\ 2. $\mathrm{PhD}$, Assistant Professor and Head of Department Of Removable Prosthodontics National Research Centre. \\ 3. $\mathrm{PhD}$, Lecturer of Removable Prosthodontics Faculty of Oral and Dental Medicine.
}

\section{Manuscript Info}

\section{Manuscript History}

Received: 31 December 2016

Final Accepted: 17 January 2017

Published: February 2017

\section{Key words:-}

Centric relation (Centric relation recording,Centric relation recording techniques,Centric relation occlusion,Centric relation record,an appraisal of the literature on Centric relation )

Neuromusclar occlusion Occlusal splint (Occlusal splints, Occlusal splint therapy,Occlusal splint bruxism, Occlusal splints bruxism, Occlusal splint ,soft Occlusal splint, soft Occlusal splint ,Occlusal splint and bruxism ,Occlusal splint tmd).

\begin{abstract}
The purpose of this study to evaluate the changes in the activity of muscles of mastication by using neuromuscular occlusion versus centric occlusion repositioning splint in treatment of myofascial pain dysfunction syndrome.

Search was made in 2 databases including PubMed and CENTRAL, title and abstract were screened to select studies comparing changes in the activity of muscles of mastication by using neuromuscular occlusion versus centric occlusion repositioning splint in treatment Articles which did not follow the inclusion criteria were excluded. Included papers were then read carefully for a second stage filter, this was followed by manual searching of biblioghraphy of selected articles. The search resulted in 5 included papers. One study evaluated the patient satisfaction, while the other 4 evaluated the masticatory function. Two of them used VAS as a measurement tool, while the other two used VAS and CAT .reducing muscle activity, relief pain clicking disappearance were the main outcomes of the included papers. Conflicting results was observed between the two types of stent.
\end{abstract}

Copy Right, IJAR, 2017,. All rights reserved.

\section{Introduction:-}

Myofacial Pain Dysfunction (MPD) is a musculoskeletal dysfunction involving malrelationship among the neuromuscular system, temporomandibular joints, and dental occlusion ${ }^{1}$

Pain, discomfort and disability associated with myofacial pain dysfunction can greatly affect a person's quality of life, as well as perpetuate a headache, commonly described by the patients as tension headache, or even cause a migraine $^{2}$

A variety of treatment modalities have been suggested including pharmacological management, occlusal appliances, physiotherapy and many others Occlusal splints are removable interocclusal appliances that are usually fabricated out of hard acrylic ${ }^{3}$

The objectives of splint use in the treatment of temporomandibular disorders (TMD) and myofascial pain dysfunction (MPD) include: eliminating occlusal interferences, stabilizing tooth and joint relationships, passive 
stretching of the musculature to reduce abnormal muscle activity, decreasing parafunctional habits, protecting against tooth abrasion and decreasing joint loading ${ }^{(4,5)}$

Repositioning splints: Plane bite splints increase the vertical diamension but should not affect the position of the mandible when habitual clenching occurs on the splint. It guide mandible into a different position at closing, which is supposed to facilitate repositioning of the disk and reduce the load on retrodiscal pain sensitive areas ${ }^{6}$

In the natural dentition a slide from centric relation (CR) to centric occlusion (CO) takes place mostly with a vertical and sometimes also with a lateral shift in the mandible's position. One important goal in the fabrication of a plane splint is to create an area around the contacts at habitual closing (neuromuscular position) which makes it possible for the mandibular teeth to move from CR to a CO position without such vertical or lateral shifts ${ }^{7}$

The maxillo-mandibular realignment theory proposes that the mandible is malpositioned relative to the maxilla at the position CR. It is believed that if the mandible is repositioned, a more optimum maxillo-mandibular relationship can be evolved, and the symptoms eliminated ${ }^{8}$

However CR cannot be properly registered in most patients with acute signs and symptoms of TMJ disorders. It may even be contraindicated to try to make such a registration. Any pushing of the mandible in a patient with TMJ inflammation and/or internal derangement can increase tissue injury ${ }^{9}$

For myofascial pain dysfunction syndrome patients receiving superior repositioning splints, would the use of splint with neuromuscular occlusion result in less pain intensity and improve muscle activity or not

The aim of this study to evaluate the changes in the activity of muscles of mastication by using neuromuscular occlusion versus centric occlusion repositioning splint in treatment of myofascial pain dysfunction syndrome.

\section{Materials and Methods:-}

Search Strategy:-

An Electronic Search of the literature was performed on PubMed Cochrane, using the following search terms

:-

1. Dentulous Jaw

2. Centric relation recording,

3. Centric relation occlusion,

4. Centric relation record

5. Occlusal splints

6. Occlusal splint therapy

7. Occlusal splint bruxism

8. Soft Occlusal splint

9. Hard occlusal splint

10. Occlusal splint and bruxism,

11. Occlusal splint tmd

12. Nuromusclar splint

13. Oral splint

14. TMD

15. Disc displacement with reducation

16. Disc displacement

17. 17- 9 OR 10 OR 11 OR 12 OR 13 OR 14 OR 15 OR 16

18. 8 AND 17

Hand search was done on the bibliography of the included papers. Last hand search was performed on the $25^{\text {th }}$ of April - 2016

Selection criteria:-

Clinical trials comparing different occlusal splints for the dentulous patients were selected according to the following inclusion criteria:-

- Human studies 
- $\quad$ Clicking

- $\quad$ Limited mouth opening

- Complete dentulous

\section{Study Selection:-}

Retrieved titles were all screened, and all papers that met the inclusion criteria were selected. Abstracts of all headings chosen were screened and obtained for inclusion criteria. After absracts were screened, full text studies were retrieved for the selected papers. In case both the heading and the abstract of an article wasn't enough to obtain data needed to make a decision regarding inclusion criteria, full texts were retrieved. Full text papers meeting inclusion criteria were screened upon their methodology and results. Two reviewers performed the screening procedure.

\section{Results:-}

A total of 504 titles were identified by the electronic search. After initial titles and abstracts screening, 495 irrelevant articles were excluded and a total of 8 articles were selected for full-text screening. No additional articles were found through hand searching. After full text screening, 5 articles ${ }^{(10-16)}$ were included in the present analysis. Were study was excluded as edentulous patients were included which didn't match the inclusion criteria ${ }^{(17,19)}$ also other study was excluded as the study had surgical procedures before splint placement. ${ }^{18}$ (Figure 1).

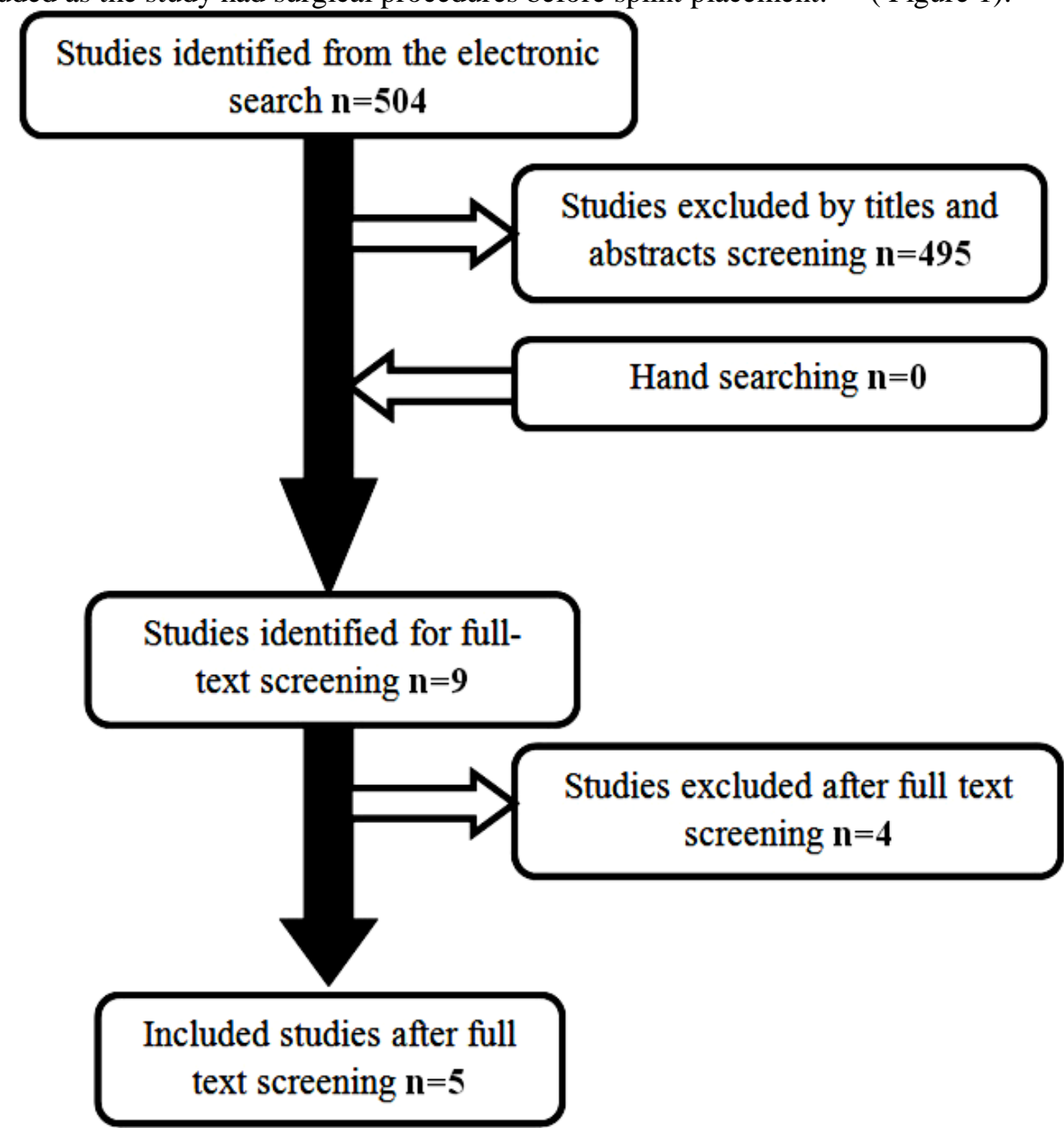

The 5 articles included in this study were published in a period ranging from 1995 to 2012 . They differed widely with respect to methodology, study designs and outcomes So the possibility of attempting a meta analysis was eliminated. (Table 1) 
Table 1:- Included Studies.

\begin{tabular}{|c|c|c|c|c|}
\hline Study & Arch & \multicolumn{2}{|c|}{ Age(years) } & Outcome \\
\hline $\begin{array}{c}\text { Nasseret,alBraz Oral } \\
\text { Res. } 2012 \\
\text { Nov,Dec;26(6):530-5. } \\
\text { Epub 2012 Sep } 27 \\
\end{array}$ & mandible & $\mathrm{N}$ & $\mathrm{N}$ & $\begin{array}{l}\text { Pain relief } \\
\text { Patient satisfaction } \\
\text { Increase mouth opening }\end{array}$ \\
\hline $\begin{array}{c}\text { Nandaet,al, Indian J } \\
\text { Dent Res. 2011 } \\
\text { Mar,Apr;22(2):303-8 }\end{array}$ & mandible & $\mathrm{N}$ & $\mathrm{N}$ & Patient satisfaction \\
\hline $\begin{array}{l}\text { Cooper BC.N Y State } \\
\text { Dent J. 1995 } \\
\text { Nov;61(9):48-53. } \\
\end{array}$ & mandible & $\mathrm{N}$ & $\mathrm{N}$ & Patient satisfaction \\
\hline $\begin{array}{l}\text { M Ziad Al-Ani, Stephen } \\
\text { J Davies, Robin JM } \\
\text { Gray, Philip Sloan and } \\
\text { Anne-Marie Glenny } \\
\text { January } 2009\end{array}$ & maxilla & 6 & 7 & $\begin{array}{l}\text { Pain relief } \\
\text { Patient satisfaction } \\
\text { Increase mouth opening }\end{array}$ \\
\hline $\begin{array}{c}\text { Frisardi G.J Prosthet } \\
\text { Dent. 1995 } \\
\text { Aug;68(2):355-60. } \\
\end{array}$ & maxilla & $\mathrm{N}$ & $\mathrm{N}$ & Increase mouth opening \\
\hline
\end{tabular}

pain analysis:-

Four studies ${ }^{(18-21)}$ has evaluated the ability for pain relief within comparison of two groups of patients . A 100 scale VAS (mm) was used to asses the ability to speak for all the four studies. No significant difference between

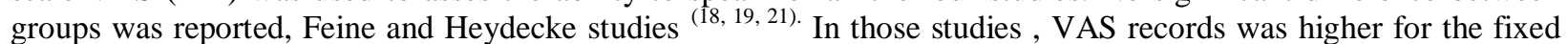
group in studies ${ }^{(18,19)}$, while in Heydecke study ${ }^{(21)}$, VAS was higher for the removable group . While a significant difference in favour of the removable group was reported in study ${ }^{(20)}$.

A single study ${ }^{(21)}$ has reported into depth the speech quality \& errors by using a fixed prosthesis in one trial and a removable prosthesis in another trial. This study tested stops, fricatives \& vowels between both the removable and fixed groups. The study revealed a statistically significant difference for the favour of the removable group in case of correctly produced sounds, specially for stops \& fricatives, while non significant difference was observed for vowels, with higher means for the removable prosthesis.

\section{Electromyographic activity of the masticatory:-}

- all studies have evaluated the efficiency of mastication between oral splints . Jaw mastication muscles, and mandibular movements were recorded using an electromyographic activity. It was reported that There were no statistically significant differences in the electromyographic activity of the masticatory muscles in the different time periods The use of a Lucia jig over $0,5,10,15,20$ and 30 minutes did not promote any statistically significant increase in muscle activity ${ }^{(22}$

Patient satisfaction:-

Four studies ${ }^{(18-21)}$ reported the patient satisfaction with different reporting methods and outcomes. Two studies ${ }^{(18,}$ ${ }^{20)}$ out of four has used a $100 \mathrm{~mm}$ VAS (Visual Analouge Scale) and CAT (Categorical Scales), to asses the patient own words in describing his satisfaction about the splint in different aspects, while the other two ${ }^{(19,21)}$ only used VAS. (Table 2)

In studies ${ }^{(18-20)}$ using the VAS, Significant difference was obvious between the treatment groups regarding rapid pain relief in favour of the centric splint, while non significant difference between both groups was reported regarding the clicking disappearance, ${ }^{(18,19)}$.

Increase mouth opening was significantly better for the repositioning splint in studies ${ }^{(18,19)}$. On the contrary it was significantly better in favour of nuromusclar splint in study ${ }^{(17)}$, while no significant difference was noticed in study ${ }^{(20)}$ between both groups . 
A contradicting outcome evaluating the general satisfaction between the two groups gave a significant difference for the centric splint group in study ${ }^{(20)}$, while reporting no significant difference between studied groups in study ${ }^{(18)}$, with higher VAS means for the repositioning splint group

\section{Discussion:-}

Patients with any systemic disease were excluded from the study to decrease the variables between groups and also to be sure for the right effect of the stent ${ }^{(21.22)}$

Occlusal splint is "Any removable artificial occlusal surface used for diagnosis or therapy affecting the relationship of the mandible to the maxillae. It may be used for occlusal stabilization, for treatment of TMJ disorders, or to prevent wear of dentition." The appliance can be made to cover the occlusal surfaces of maxillary or mandibular teeth and can be fabricated from many different materials, giving it a hard, soft, or intermediate feel. ${ }^{(23)}$

Splint therapy is considered an adjunct to pharmacologic therapy and most appropriate when nocturnal parafunctional activities can be identified. Typically, a flat-plane maxillary occlusal splint designed for bilateral contact of all teeth is fabricated. ${ }^{(24)}$

It has been hypothesized in the literature that the presence of a foreign object in the palate may reduce nocturnal jaw muscle activity, possibly due to changes in the oral tactile stimuli, a decrease of oral volume, and space for the tongue ${ }^{(25)}$

It has also been hypothesized that an intraoral splint may make the patient aware of the position and potentially harmful use of the jaw this has been labeled a "cognitive awareness" concept.

Disc displacement with reduction (DDWR) of TMJ is common in TMD clinics. Patients usually present with a complaint of joint sounds, and only few patients present with persistent TMJ pain or locking of the jaw. MRI is a standard diagnostic tool for DDWR but the goals of treatment are to reposition the disc, eliminate the joint sounds and pain, and achieve rehabilitation of jaw functions. ${ }^{(26)}$

Although joint sounds and disc displacement without pain or impaired jaw functions were considered less important clinically, the elimination of sounds contributes to a patient's well being. ${ }^{(27)}$

A normal disc position might prevent more severe diseases from occurring early, making a noninvasive method with a short therapeutic time and less complications preferable to radical surgery or ignoring the problem. ${ }^{(28)}$

It was believed that different TMDs need different splint designs and various treatment regimens. Although upper stabilization splint is good for muscle disorders and bruxism, ARS might be suitable for DDWR, but each has its own shortcomings, which need to be overcomed. These are open bite, difficulty having normal diet when wearing the appliance, and osteoarthrotic changes in the condylar form. ${ }^{(29)}$

Some patients need complex dental treatment for stabilization of occlusion. Splint therapy for TMDs may be classified into three major groups on the basis of splint functions: stabilization splints (centric splints) the neuromuscular splints, and ARS ${ }^{30}$

The stabilization splint provides a balanced bilateral occlusal contact on a flat splint surface; during lateral ${ }_{31}$ movement, only cuspids are in contact with the splint this method is used to stabilize occlusion, muscles, and joints.

The ARS is used to treat DDwR and DDwoR The treatment goals of splint for DDwR of TMJ are to reposition the condyle downward and recapture the disc anteriorly, correct the relationship between the glenoid fossa, articular disc, and condyle ,improve jaw function, reduce joint pain and sounds, eliminate mechanical interference and prevent progression of the disorder ${ }^{(32)}$

We elevated the bite vertically just enough to eliminate the joint sounds, but we did not reposition the jaw anteriorly in three groups however, the conventional ARS was designed to protrude the mandible anteriorly to varying amounts. ${ }^{(33)}$ 
Treatment time should be long enough to recapture and to stabilize the disc, and the splint should be removed gradually. Although the length of treatment time is still controversial, we suggest 4-8 weeks, followed by slow weaning off to avoid surgery and post treatment occlusal therapy (prosthetic or orthodontic treatment). ${ }^{34)}$

In this study, we were able to perform MRI in patients to confirm the diagnosis and results of treatment this make proper diagnoses of the internal derangement before treatment. The MRI examination on patients showed a high correlation between clinical examination and MRI image finding. ${ }^{35)}$

A plastic sheet was used to be sure of standardization of position of electrode during period of follow up using fixed anatomical landmarks.

Although surface electromyography has been presented for long time as a method in dental medicine for muscular activity research and evaluation, there is no evidence about its role in TMD diagnosis. While one group of authors disagrees with regard to EMG in TMD diagnosis and treatment evaluation, others stressed on its major role in diagnosing alterations in neuromuscular function considering both views, in this investigation our aim was to evaluate masticatory muscle activity alterations in TMD patients. ${ }^{(38)}$

The use of electromyography in temporomandibular dysfunction diagnosis is based upon the hypothesis that various pathologic and dysfunctional conditions, such as muscle hyperactivity, muscle fatigue and muscle imbalance, can be detected from the EMG recording. The term muscle hyperactivity has been used to describe any increased muscular activity over and above that necessary for function. Muscle hyperactivity thus includes not only the parafunctional activities of clenching, bruxing, and other oral habits but also any general increase in the level of muscle tonus. ${ }^{36)}$

In the first instance, EMG signal analyses are qualitative with the inspection of the raw signal in the last decades, the application of mathematical models and statistical analyses has offered a better understanding of EMG signal properties, allowing the evaluation of the physiologic events of muscles. Such advances have made it possible to study muscle electrical manifestations in amplitude domain as well as wave frequency. ${ }^{37}$

However this investigation has confirmed that EMG is a useful and non-invasive method in TMD diagnosis. However, EMG is not sufficient if applied alone, but together with other methods it forms a complementary approach in TMD diagnosis. ${ }^{(39)}$

The maxillo-mandibular realignment theory proposes that the mandible is malpositioned relative to the maxilla at the position of maximum tooth intercuspation (CR). It is believed that if the mandible is repositioned, a more optimum maxillo-mandibular relationship can be evolved, and the symptoms eliminated. ${ }^{(40,41)}$

More than one type of scale is used to measure patient's satisfaction. Out of those is the OHIP (Oral Health Impact Profile) which is meant to provide information about perceptions of oral health however, the complete 49 item version is not always applicable in a clinical study because its time consuming. This led to the development by Slade , a simplified version, the OHIP-14 ${ }^{(36)}$. This questionnaire includes 14 items, two from each domain, selected because they have been shown to be the most frequently reported. The OHIP questionnaire includes seven main scopes ${ }^{(37)}$. Another type is the Visual analogue scales (VAS) and categorical scales (CAT) which are known to be predictible assessment tools ${ }^{(38)}$.VAS, is frequently used to measure subjective perceptions, while CAT questions are used to collect information about the patients' physical, psychological function and general health. Patients are asked to choose a word from a four-point scale that best described their response. Our included studies used a VAS scale from 0 to 100 , other authors have used VAS with scores from 0 to 10 or from 1 to $5^{(39)}$. The need for multidimensional evaluation of implant therapy, using consistent instruments and valid tools when available, has been displayed in literature for many years ${ }^{(40)}$.

Conflicting results in our systematic review, is mainly due to lack of randomization in all of the included studies ${ }^{(18-}$ 21) , outcomes vary obviously when true randomization takes place, rather than a patient centered protocol, in matter of directing patients to a specific treatment group. Follow up period wasn't enough to judge satisfaction scores, only two months were given for patients to test their perception. Only five studies were included in our review, which isn't a valid number to synthesize a definitive conclusion about the treatment options. In two studies 
${ }^{(19,21)}$ only a single scale measurement (VAS) was used while its recommended to use more than one assessment tool for more reliable outcome results.

The degree of patient satisfaction is the result of a complicated interaction between psychological and physiological factors ${ }^{(45)}$. Even though, up till now, there is no any accurate scale or a questionnaire with items related to personal behavioral habits, which might be relevant for motivating the patient to shift their choices towards a specific prosthesis design, keeping in mind conservation of the oral tissues functions ${ }^{(46)}$.

\section{Conclusion:-}

This study clarified that Temporary splint does not cause permanent or irreversible changes in the structure or position of the jaw or teeth. It has better patient compliance, fewer side-effects, and is more cost-effective than surgical treatment

Splint using centric relation record has a greatest patient satisfaction and easy in manipulation , Pain relief was achieved in all groups use of repositioning splints might be very useful in the initial management of TMJ pain and dysfunction. Decreased internal pressure and relieve of retrodiscal tissues ,There are different types of occlusal appliances, each one has its special design, indication and precautions that should be followed so that it was strongly advised to thoroughly understand the masticatory system dynamics and perform a comprehensive examination to the TMJ and its related structures to be able to choose correct appliance perfectly with fewer complications, Further and bigger randomized controlled trials need to be conducted to verify the findings.

\section{References:-}

1. Mujakperuo HR, Watson M, Morrison R, Macfarlane TV (2010). "Pharmacological interventions for pain in patients with temporomandibular disorders". The Cochrane Database of Systematic Reviews.pp.67.

2. Hersen, Peter; Sturmey, Michel (2012). "Handbook of evidence-based practice in clinical psychology."Hoboken, NJ: Wiley. pp. 594-610.

3. Zadik, Y; Drucker, S (2011). "Diving dentistry: a review of the dental implications of scuba diving". Australian dent. J. vol. 56 no. (3) Pp.33.

4. Edwab RR, (2003). "Essential dental handbook: clinical and practice management advice from the experts. Tulsa, OK, Penn Well" pp.55-67.

5. Cawson RA, Odell EW, Porter S (2002). "Cawsonś essentials of oral pathology and oral medicine (7th ed.). Edinburgh: Churchill Livingstone". Pp.88-112.

6. Scully, Crispian (2008). "Oral and maxillofacial medicine: the basis of diagnosis and treatment (2nd ed.). Edinburgh: Churchill Livingstone. "Pp.155-180.

7. OBERT L. GAUER, MICHAEL J. SEMIDEY, Womack Army, (2015)"Diagnosis and Treatment of Temporomandibular Disorders "; vol.91 no. (6) pp.:378-386.

8. Greenberg MS, Glick M. (2003). "Burket's oral medicine diagnosis \& treatment " (10th Ed.). Hamilton, Ont: BC Decker pp.44-56.

9. Kindler LL, Bennett RM, Jones KD (2011). "Central sensitivity syndromes: mounting pathophysiologic evidence to link fibromyalgia with other common chronic pain disorders". Pain Management nursing vol.12 no. (1): pp.15-24.

10. Eric Schiffman et al (2014) "Diagnostic Criteria for Temporomandibular Disorders (DC/TMD) for Clinical and Research Applications: Recommendations of the International RDC/TMD Consortium Network ${ }^{*}$ and Orofacial Pain Special Interest Group ${ }^{\dagger} "$ J. Oral Facial Pain Headache.vol.; 28 no.(1): pp.6-27.

11. Nanda A, Jain V, Srivastava A 2011. An electromyographic study to assess the minimal time duration for using the splint to raise the vertical dimension in patients with generalized attrition of teeth. Indian J Dent Res. Mar-Apr;22(2):303-8.

12. Grubwieser G, Flatz A, Grunert I, Kofler M, Ulmer H, Gausch K, Kulmer S. 1999 Quantitative analysis of masseter and temporalis EMGs: a comparison of anterior guided versus balanced occlusal concepts in patients wearing complete dentures. J Oral Rehabil. Sep;26(9):731-6.

13. Zuccolotto MC, Nóbilo KA, NunesLde J, Hotta TH. 1999 Sliding plates on complete dentures as a treatment of temporomandibular disorder: a case report. Cranio. Oct;17(4):289-92.

14. M Ziad Al-Ani , Stephen J Davies, Robin JM Gray, Philip Sloan and Anne-Marie 2009 Stabilisation splint therapy for temporomandibular pain dysfunction syndrome Glenny January 
15. Nassar MS, Palinkas M, Regalo SC, Sousa LG, Siéssere S, Semprini M, Bataglion C, Bataglion C. 2012 The effect of a Lucia jig for 30 minutes on neuromuscular re-programming, in normal subjects. Braz Oral Res. Nov-Dec;26(6):530-5. Epub Sep 27.

16. Cooper BC. 1995 The role of bioelectronic instruments in the management of TMD. N Y State Dent J. Nov;61(9):48-53.

17. Neff P. 1995 Trauma from occlusion. Restorative concerns. Dent Clin North Am. Apr;39(2):335-54. Review.

18. Frisardi G.J 1992 The use of transcranial stimulation in the fabrication of an occlusal splint. Prosthet Dent. Aug;68(2):355-60.

19. Alomar, X; Medrano, J; Cabratosa, J; Clavero, JA; Lorente, M; Serra, I; Monill, JM; Salvador, A (2007). "Anatomy of the temporomandibular joint". Seminars in ultrasound, CT, and MRI vol. 28 no. (3) Pp.45.

20. Standring S, ed. (2006). "Gray's anatomy: the anatomical basis of clinical practice" (39th Ed.). Edinburgh: Elsevier Churchill Livingstone. pp.88.

21. Aggarwal VR, Lovell K, Peters S, Javidi H, Joughin A, Goldthorpe J (2011). "Psychosocial interventions for the management of chronic orofacial pain". The Cochrane Database of Systematic Reviews no. (11):pp.35.

22. Cairns, BE (2010). "Pathophysiology of TMD pain-basic mechanisms and their implications for pharmacotherapy". J. of oral rehab. Vol.11 no. (3): pp.77-89.

23. Shilpa Shetty; Varun Pitti; C. L. Satish Babu; G. P. Surendra Kumar; B. C. Deepthi (September 2010). "Bruxism: a literature review". J. of Ind.Prosthodont. Society vol.10 no. (3): pp.141-150.

24. De Meyer, MD; De Boever, JA (1997). "The role of bruxism in the appearance of temporomandibular joint disorders". Revue belge de medecine dentaire vol.52 no. (4): pp.124-38.

25. Manfredini, D; Lobbezoo, F (June 2010). "Relationship between bruxism and temporomandibular disorders: a systematic review of literature from 1998 to 2008". Oral surgery, oral medicine, oral pathology, oral radiology, and endodontics .vol.109 no. (6): pp.35.

26. Anderson, GC; Gonzalez, YM; Ohrbach, R; Truelove, EL; Sommers, E; Look, JO; Schiffman, EL (2010). "The Research Diagnostic Criteria for Temporomandibular Disorders. VI: future directions". J.of orofacial pain vol. 24 no. (1): pp.79-88.

27. Carlsson GE.( 2010) " Some dogmas related to prosthodontics, temporomandibular disorders and occlusion. " Acta Odontol Scand; vol.68: pp.313-22.

28. Wassell R, Naru A, Steele J, Nohl F (2008). "Applied occlusion. London: Quintessence. "pp. $73-84$.

29. Davies S, Gray RM (2001). "What is occlusion?" British Dental J. vol.191 no. (5):pp.66-80.

30. William Maixner, et,al (2011): "Orofacial Pain Prospective Evaluation and Risk Assessment Study". - The OPPERA Study J Pain. Vol.12: no. (11): pp.35.

31. Beaton RD, Egan KJ, Nakagawa-Kogan H, Morrison KN. (1991) "Self-reported symptoms of stress with temporomandibular disorders: comparisons to healthy men and women." J. of Prosthet. Dent.; vol.65: pp.289293.

32. Warren M.P. and Fried J.L. (2001) "Temporomandibular Disorders and Hormones in Women Cells Tissues

J.of Prosthet. Dent. Vol. 169, No. (3), pp.25.

33. Leslie R. Halpern, Linda M. Kasten (2013) "Evidence-Based Women's Oral Health", An Issue of Dental Clinics, vol (57) no2:pp.45.

34. Badel T, Savić Pavičin I, Podoreški D, Marotti M, Krolo I, Grbeša Đ. (2011) "Temporomandibular joint development and functional disorders related to clinical otologic symptomatology. " Acta Clin Croat; vol. (50):pp.51-60.

35. Farrar WB. (1972): "Differentiation of temporomandibular joint dysfunction to simplify treatment". J .Prosthet. Dent.; vol.(28) pp.:629

36. Odell EW (Editor) (2010). "Clinical problem solving in dentistry". (3rd Ed.). Edinburgh: Churchill Livingstone. pp. 37-41.

37. Hupp JR, Ellis E, Tucker MR (2008). "Contemporary oral and maxillofacial surgery ". (5th Ed.). St. Louis, MO: Mosby Elsevier. pp. 629-47.

38. Hoffmann RG, Kotchen JM, Kotchen TA, Cowley T, Dasgupta M, Cowley AW Jr. (2011): "Temporomandibular disorders and associated clinical comorbidities." Clin J Pain; no (27) pp.:268-74.

39. Rutkiewicz T, Kononen M, Suominen-Taipale L, Nord-blad A, Alanen P. (2006) " Occurrence of clinical signs of temporomandibular disorders in adult Finns".. J. Orofacial Pain. vol.20: pp.208-17..

40. Conti PC, dos Santos CN, Kogawa EM, de Castro Ferreira Conti AC, de Araujo Cdos R. (2006) "The treatment of painful temporomandibular joint clicking with oral splints: a randomized clinical trial." J. Am. Dent. Assoc.;vol.(137): pp.1108-14. 
41. Deng M, Long X, Dong H, Chen Y, Li X. (2006) "Electrosonographic characteristics of sounds from temporomandibular joint disc replacement. " Int. J. Oral Maxillofac Surg;vol.(35)pp.:456-460.

42. Mazzetto MO, Hotta TH, Carrasco TG, Mazzetto RG. (2008) "Characteristics of TMD noise analyzed by electrovibratography. " J. Cranio. mandib. Pract;vol. (26): pp. 1-7.

43. Garcia AR, Folli S, Zuim PRJ, Sousa V. (2008): "Mandible protrusion and decrease of TMJ sounds: an electrovibratographic examination". Braz Dent J;vol. (19):no.77-82.

44. Olivieri KA, Garcia AR, Paiva G, Stevens C. (1999) "Joint vibrations analysis in asymptomatic volunteers and symptomatic patients. Cranio"; vol., (17):PP.176-183.

45. Dworkin SF, Huggins KH, LeResche L, Von Korff M, Howard J, Truelove E, et al. (1990): Epidemiology of signs and symptoms in temporomandibular disorders: clinical signs in cases and controls. J. Am. Dent. Assoc.;vol.(120): PP.273-81.

46. Tecco S, Festa F, Salini V, Epifania E, D'Attilio M. (2004) "Treatment of joint pain and joint noises associated with a recent TMJ internal derangement: a comparison of an anterior repositioning splint, a full-arch maxillary stabilization splint, and an untreated control group". Cranio.vol. 22. No. (3): PP.209-19. 